\title{
Heavy Mobile Artillery
}

\section{Its Value as an Asset for Defense in the United States}

\author{
By Major C. E. Kilbourne, General Staff Corps, U. S. Army
}

THE use in Europe of heavy ordnance ranging from 16-inch caliber and throwing projectiles of from 400 to 2,000 pounds in weight, loaded with high explosive bursting charges, to a distance varying from six to twenty miles is too well known to need comment. These heavy guns were designed by the Teutonic powers originally for the purpose of destroying the permanent land fortifications in general use on European frontiers. Subsequently the Central powers increased the mobil of their her especially France, and England, were driven to develop ordnance of equal power for use, first, in defense, and latterly, in offensive operations.

In the United States the feeling against war is so great that it is idle to dwell upon anything relating to offensive operations. So firmly are our people wedded to the idea of defense that neither in public writings nor ad dresses do we ever hear of the offensive, though it is a known military axiom that the best defense consists in assuming the offensive at every opportunity.

Following the custom, I shall consider in this article only the defensive power of heavy movable ordnance and the importance of its development in addition to the artillery with which our Army is now supplied.

Our coast fortifications were designed: first-to protect the coast cities and anchorages, naval bases, factories and other utilities from bombardment; second, to prevent the occupation by an enemy of good harbors as bases for invasion, with many railroad lines radiating into the wealthiest parts of the counwealthiest parts of the coun-
try; third, to give safe try; third, to give safe harbor to our own fleet if
defeated, in which to refit for further operations; fourth, to cover reasonable water areas to the seaward of our harbors in which our own fleet, emerging, could take up battle formation before coming under destructive fire of a blockading enemy fleet.

For the foregoing purposes large caliber guns and mortars of great power have been mounted on concrete emplacements and supplied with accessories in the way of searchlights, submarine mines, observing and range finding stations.

Recent developments in naval ordnance have forced us to undertake the modification of our gun carriages and the emplacement of larger caliber, longer range guns, and also more extended installation of fire control systems and searchlights. All of these are necessary if the of these are necessary if the

are to be accomplished but the fortifications des have their limitations in that the guns are fixed and are effective to the extreme limit of their ranges and no further. A coast fortification is powerless against fleet or an army maneuvering a few hundred yards beyond the range of its guns.

The operations of the Japanese in the Chinese and Russian wars, the attempt of the English on the Gallipol Peninsula, and our own experience at Santiago de Cuba show plainly the method which will be pursued always in case important objectives are fortified sufficiently to resist direct naval attack; that is, an army will be landed somewhere beyond the range of the guns, marched to the rear of the fortifications (if practicable), and a combined land and naval attack will be made upon the fortified area. If these operations succeed, the saf harbor and advantageous communications for a base of harbor and advantageou

The above examples all show that the landing of large forces on beach lines is an entirely practical operation and that it can be accomplished even in the face of strong resistance provided the navy of the invading forces can support the landing troops. If the point selected for landing be a reasonably safe harbor the operations are considerably facilitated. There are instances on our own coast line where cities of major strategic importance are flanked by harbors not sufficiently valuable to be fortified, but nevertheless offering fair facilities for the disembarkation of an army. There are instances also where just beyond the range of the seacoast guns are open beaches perfectly practicable for landing operation in good weather. It is for the defense of these harbors and beaches that heavy mobile artillery is especially needed.

It is a peculiar coincidence that on both our eastern and western coasts throughout the more important strategic areas, railroad lines parallel the coast at a very short distance inland making convenient the rapid

of a power which would seriously damage, if not destroy, war vessels of the type named at ranges up to nine miles, the situation would be entirely changed. The transports and supporting warships would be forced to retire to such a distance that small caliber gunfire could no longer reach the shore. At the same time the distance which troops in small boats would have to travel would be multiplied, increasing the time in which our troops could be rushed to the threatened point. The defending field artillery and machine guns could fire upon the boats when they were comparatively close to shore, since at the distance the battleships would lie, they could not support the actual landing even with their turret gun for fear of firing into their own forces.

To complicate the difficulty still further, animals could not swim ashore. The field and siege artillery, usually landed on prepared barges would have to be brought an excessive distance. The time required for landing would be greatly extended with all the danger of a storm all the danger of a storm interrupting the operations
and requiring the transports and other war vessels to take an offing, thus abandoning the troops already landed without the possibility of reinforcement or renewal of supplies until more favorable weather.

The requirements for artillery to accomplish the above results may be stated to be: First, great mobility; second, prompt entry into action as soon as they arrive within range of the enemy's vessels; third, rapid change of position in event of fire from the attacking vessels becoming so accurate as to threaten destruction; fourth, sufficient power to destroy a warship by a single blow if the vital portion of the
vessel be struck; fifth, a means of range finding which ensures to the gun the advantages of permanent emplacement and installation. Though no such type of artillery has been developed in this country there is no doubt that the nation which furnished the inventors of the machine gun, the submarine, the airplane and the turret can solve this comparatively simple problem. If prompt defense is thought necessary, we may always copy European types while improvements are under consideration.

The gun carriage must be an integral part of the railroad car and must permit of being secured by simple operations (not requiring more than two or three minutes) to a base so solid that the gun, after firing, will return to the same position, that is, we must not have to relevel the platform between shots. Such a time

Railroad howitzer car with 4.7 -inch piece, ready for transit transportation of such ordnance from place to place. As has been indicated above, landing on the beach or in the small harbor, if resisted, must be supported by the war vessels of the invader, otherwise the troops in small boats and barges will be at the mercy of the field artillery and machine guns of the defenders. Battleships of the predreadnaught class and armored cruiser (such as usually are detailed for convoying purposes) average fourteen small caliber guns to the broad-side. These guns are behind armor invulnerable to ordinary field artillery fire. Half a dozen such vessels lying within a mile of our coast line (as they could in many positions) would deliver something like 5003 - to 6 -inch projectiles a minute on any section of the beach line it was proposed to occupy. It can readily be seen that, with such a curtain of fire, the landing of troops, supplies and animals from transports lying close in shore would

If, on the other hand, we had transportable artillery be an operation of comparative ease and safety. tween shots. Such a time
all right when firing against consuming operation is all right when firing against land fortifications; the interval between shots is then unimportant due to the fact that the range does not
change. But to fire effectively at a swiftly moving target, such as a battleship, the shots must follow each other so rapidly that there will be no material change in range between shots, otherwise the correction for range error observed for one shot will not apply to the next. Positions fixed in advance for the gun are of importance from another point of view, that is, the location of observing stations for the accurate control of fire may be determined in advance and a plotting board prepared so that the gun may open accurate fire immediately on getting into action. This is necessary, since its position being evident as soon as it opens fire, the gun must begin to make hits before the battleship can determine its range accurately and deliver return fire. To hit first in artillery combat usually means to win.

Where a valuable objective, such as a city, navy yard, 
or anchorage is being protected against bombardment, it is necessary that the enemy's ships be kept beyond extreme range, guns and mortars of 16-inch caliber are necessary. But such a condition does not obtain for open beaches nor for harbors of minor importance where projectiles falling beyond the shoreline may do considerable local damage but can have no material effect on the progress of the war. For this reason, the 12-inch gun and the 12-inch mortar already developed and tested for our seacoast service are believed sufficiently powerful for our mobile armament. Assuming the average belt protection of battleships to be equal to 10 inches of Krupp steel and the deck armor to be 4 inches (which

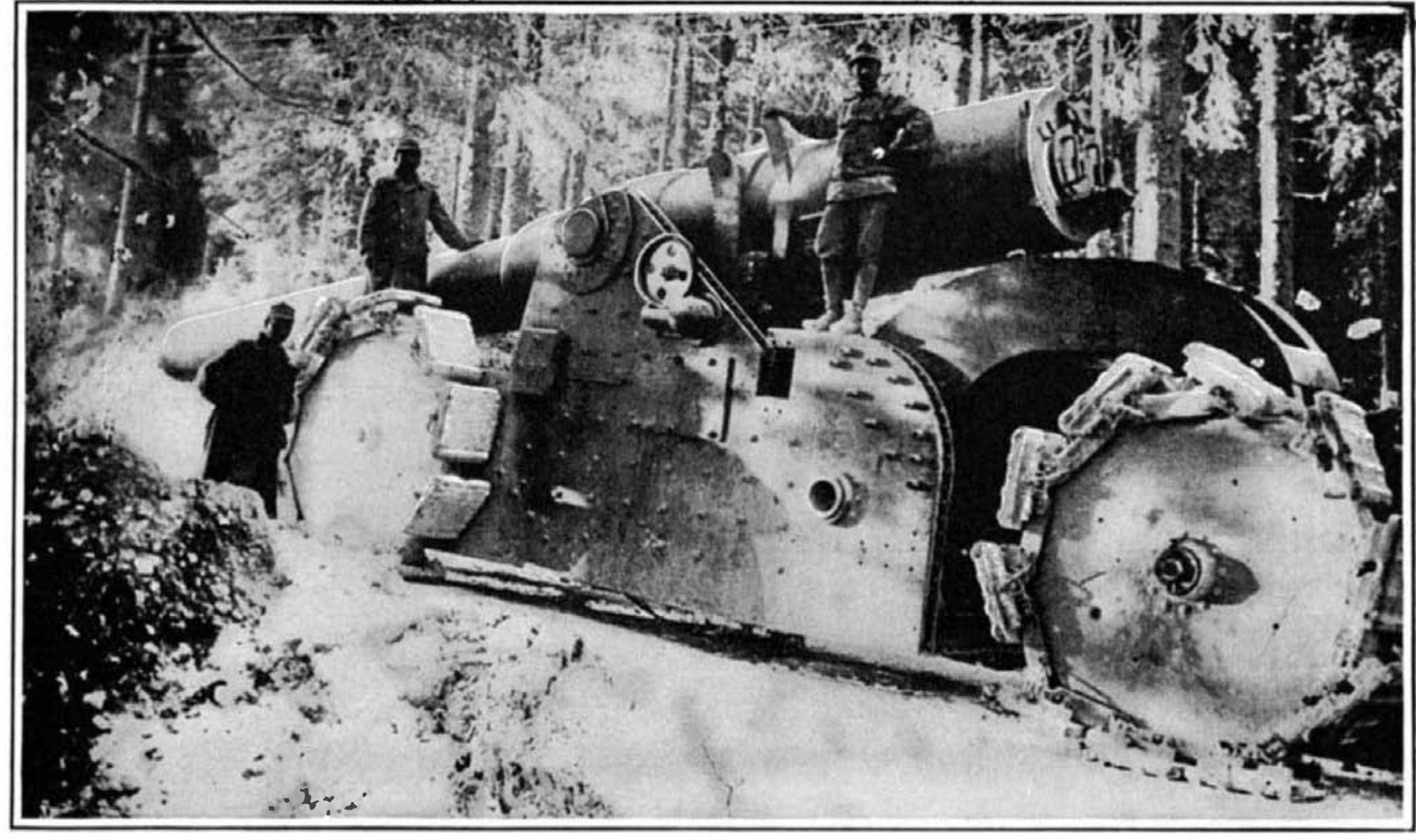

A big naval gun on pedrail mounting, in use on the Austro-Italian front

beach. No one who has ever taken part in a hard march prior to an engagement will fail to appreciate the enormous advantage to the defenders, who await the assault

The result would be further delay to the invaders and a greater opportunity for the defenders to concentrate for resistance. In other words, the lesson of Gallipoli, where the defense had time to prepare, and the invaders had finally to retire in spite of initial successes and heroic efforts.

And we must not overlook the moral effect of the possession of such ordnance. We may be certain that, in a country of all nationalities, no fixed fortification can be constructed without its exact strength being known. We may feel certain therefore, that an enemy in contemplathave), the perforation curve

impact show that the gun is capable jectile into that the gun is capable of sending a projectile into the vitals of a warship up to a range of 6 mile and to perforate casemate armor up to 11 miles, while the mortar projectile will perforate the deck armor between $22 / 3$ and 9 miles. It will be observed that the effect of the mortar increases with the range (up to the point where the lighter projectile is used), owing to the fact that the shell falls from a greater height and consequently has a greater striking velocity. These weapons used together have an effect destructive to the average warship at all ranges up to 9 miles.

It is appreciated that the warships can bombard a beach with their turret guns at this range and interfere with the concentration of the defenders. But the number of projectiles would be limited, and the defenders could take cover. The recent experiments at Pensacola prove that even the largest projectiles will not penetrate deeply in beach sand; they very quickly turn and pas out and upward. Some effect would be had, but to quote General Shafter, "A soldier must be in danger sometimes, even in war."

It may be asked why the gun and mortar effect cannot be combined in a howitzer, that is, a weapon which will give both high angle and direct fire. The reason for this is that, in order to have high angle fire from a railroad car, only a short recoil is permissible, and a high velocity gun on a railroad car must have a comparatively long recoil. The carriage for the long recoil gun would have to be very high. This would interfere in crossing covered bridges and also would lessen the stability of the mount on curves and the railroad track. For limited use the howitzers are all right, for all round utility the combination of gun and mortar is better.

A railroad unit should consist of a 12-inch gun on one car, two 12-inch mortars on another, four anti-aircraft guns on a third, an ammunition car for the gun and one for the mortars, a car for the range finding equipment and the necessary cars for the personnel.

and the necessary cars for the personnel.
Assuming that the enemy, by surprise or by an over- line established, exposed to artillery fire to which they could not reply until reaching the effective range of such artillery as they might have been able to land on the

Inches

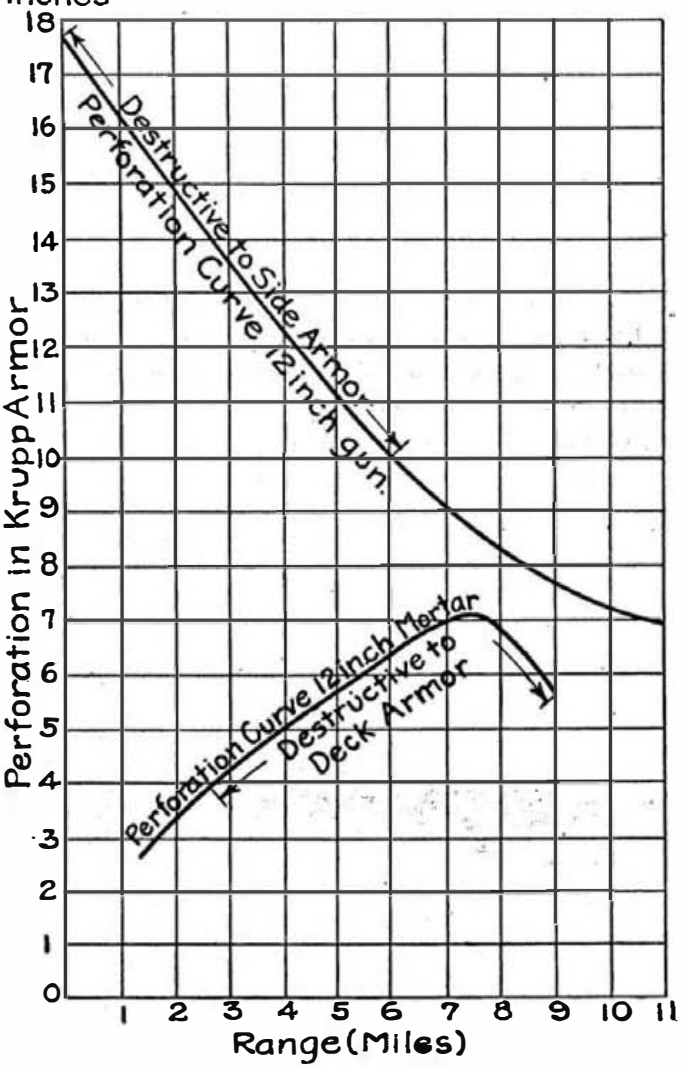

Perforation curve of a 12-inch gun compared with that The sudden fall in effect of the mortar at its extreme range is
due to the use of a lighter projectile: its perforating power howdue to the use of a lighter projectile: its perforating power, however, is greater than the res.
deck placed on battleships.

ing an attack would lay his plans to overcome what he knows is prepared.

But if we had a large number of heavy movable guns and mortars he could not count upon their position Three days would take them from Portland to Key West. Nor could an enemy count upon unresisted landing at any point on our coast line. By feints he might cause us to deflect the movable artillery to other points than the one selected for attack, but he could never be certain. No nation attacks another without first making plans promising a successful outcome of the venture. Anything tending to render success doubtful will operate to complicate the plan and possibly to prevent the attack entirely. The writer knows of no single preparation which will so strengthen our defensive powers as the provision of powerful, long range, movable artillery.

\section{The Current Supplement}

W ${ }^{\text {HILE many new varieties of woods for interior }}$ finish and fine cabinet work have been made available of late years, mahogany still maintains its place as one of the best for high-class work that has ever been discovered. In the article on The Mahogany Tree, in the current issue of the Scientific American SuppleMENT, No. 2148, for March 3, 1917, much valuable information is given in relation to this material and its sources, and the article is accompanied by a number of unusually fine photographs. A short note recently appeared in these columns on a paper on Some Present Day Technochemical Problems, by Dr. Bacon, Director of the Mellon Institute, but the subject is of such importance that the presentation of the entire paper appears to be desirable, and it will be found in this issue of the Supplement. Trenching Machinery illustrates and describes some power devices now extensively employed in engineering operations where large quantities of earth must be handled. Tenacity of Life in Insects is a short account of the vitality exhibited by a moth which wa mounted for a collection. It is accompanied by a whelming preponderance in artillery, succeeded in forcing a landing in spite of resistence, the heavy mobile artillery would be a strong reinforcement to the defenders during the land camfenders during the land campaign. It is certain that
artillery of this character artillery of this character could not be landed on a beach, and that, until the invader had secured a harbor with first class docking facilities the defenders would outclass him in ordnance. The progress of the invaders progress of the invaders
toward their objective by toward their objective by land would be seriously hampered by reason of the fact that they could not establish an open camp within range of such guns and mortars. Their exact location would be known to the defenders who could force them, by artillery fire, to dig in for cover if they ventured within range.

This would mean a march of from nine to eleven miles before they could make an assault upon any defensive

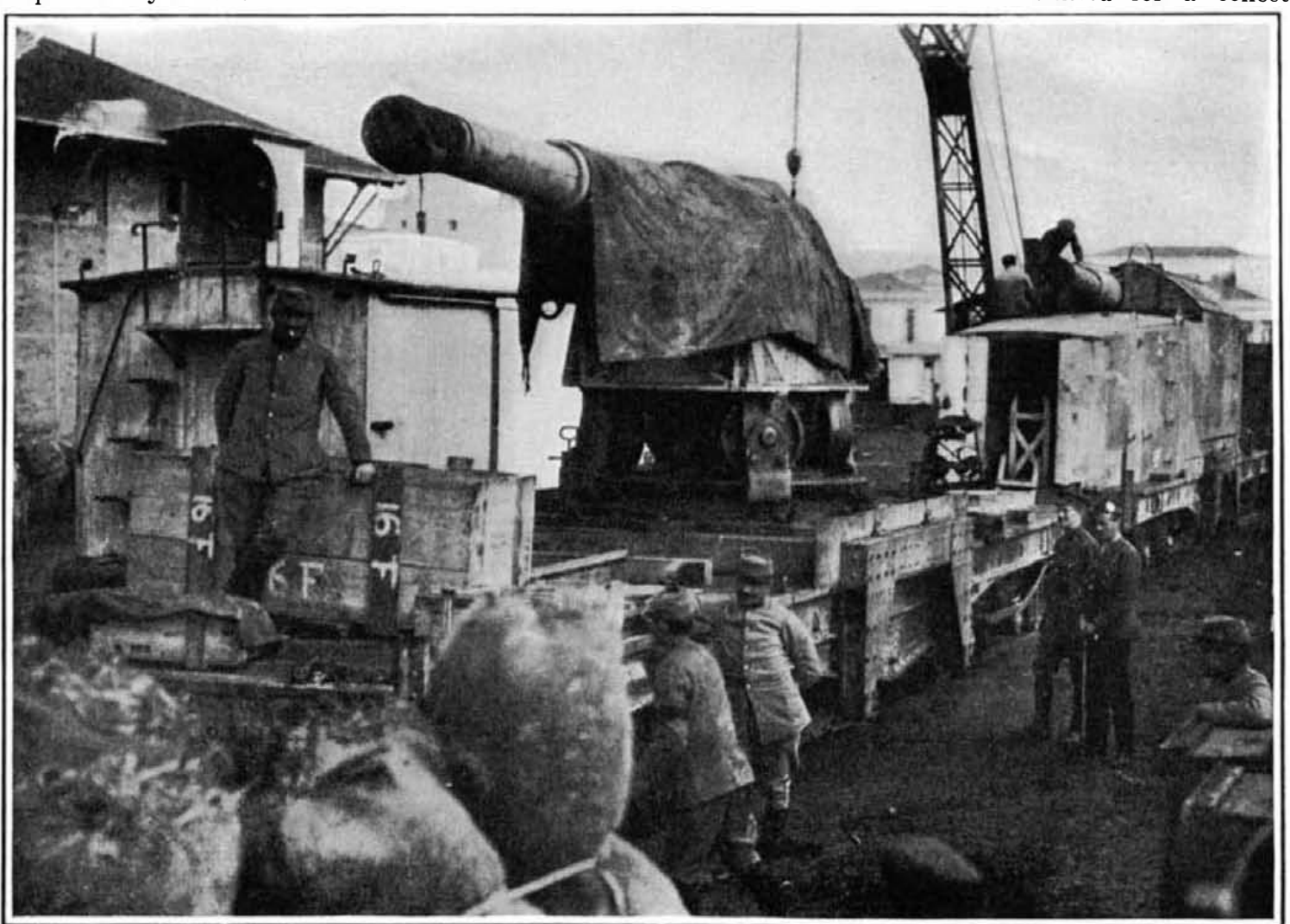

Mobile artillery used by the British at Salonica photograph of the insect. Photomicrographyfor the A mateur describes a new method of doing this interesting kind of photographic work that is both simple and inexpensive. It is accompanied by a number of explanatory diagrams and specimens of the work produced. Electrical Treatment of the Wounded describes recent methods that have been developed during the war in Europe with most gratifying results. An article on Seaveeds gives an interesting account of their economic uses and possibilities.

Magnetic Damping of Mercury

THE Bureau of Standards 1 has devised an electromagnetic method of damping waves and other disturbances in mercury in barometers and other measuring instruments. It is expected that this method will be found extremely useful in increasing the accuracy of measurements taken at sea. 